\title{
Pengaruh Koordinasi terhadap Efektivitas Pelayanan Kampung Keluarga Berencana Kabupaten Sumedang
}

\author{
The Effect of Coordination on The Effectiveness Service of The \\ Family Planning Village in Sumedang Regency \\ Dhesti Widya Nurhasanah Ningrum* \\ Sekolah Tinggi Ilmu Aadministrasi Sebelas April Sumedang, Indonesia
}

Diterima: 27 Agustus 2019; Disetujui: 21 September 2019; Dipublish: 6 Januari 2020

\begin{abstract}
Abstrak
Program Kampung Keluarga Berencana di Kabupaten Sumedang sudah berlangsug sejak tahun 2016. Hingga saat ini pembentukan kampung KB terus berlanjut dengan membentuk satu kampung KB disetiap Kecamatan sehingga total Kampung Keluarga Berencana di Kabupaten Sumedang sebanyak 27 Kampung Keluarga Berencana. Tujuan dari penelitian ini adalah untuk mengetahui pengaruh koordinasi terhadap efektivitas pelayanan Kampung Keluarga Berencana di Kabupaten Sumedang. Metode penelitian yang digunakan adalah metode kuantitatif, yang bertujuan mendeskripsikan dan menjelaskan keberadaan variabel-variabel secara faktual, serta hubungan antara variabel yang satu dengan yang lainnya. Analisis data yang digunakan meliputi Perhitungan Prosentase, Perhitungan Sperman Rank, Uji Korelasi, Uji Signifikasi serta Uji Determinasi. Berdasarkan hasil penelitian diperoleh hasil bahwa pengaruh koordinasi terhadap efektivitas pelayanan kampung KB sebesar 86\%. Sehingga dapat disimpulkan bahwa koordinasi memiliki pengaruh yang besar terhadap efektivitas pelayanan.
\end{abstract}

Kata Kunci: Koordinasi, Efektivitas Pelayanan, Kampung Keluarga Berecana

Abstract

The Family Planning Village Program in Sumedang Regency has been going on since 2016. Until now the formation of the Family Planning villages continues to form one KB village in each Sub-District so that the total number of Family Planning villages in Sumedang Regency is 27 Family Planning villages. The purpose of this study was to determine the effect of coordination on the effectiveness of family planning services in Sumedang Regency. The research method used is a quantitative method, which aims to describe and explain the existence of variables factually, as well as the relationship between variables with one another. Analysis of the data used includes the Calculation of Percentage, Calculation of Sperman Rank, Correlation Test, Significance Test and Determination Test Based on the results of the study found that the effect of coordination on the effectiveness of family planning services is $86 \%$. So it can be concluded that coordination has a great influence on the effectiveness of services.

Keywords: Coordination, Effectiveness, Family Planning Village.

How to Cite: Ningrum, D.W.N, (2020). Pengaruh Koordinasi terhadap Efektivitas Pelayanan Kampung Keluarga Berencana Kabupaten Sumedang. PERSPEKTIF, 9 (1): 46-54

*Corresponding author:

E-mail: dhesti.widya@stiasebelasapril.ac.id
ISSN 2085-0328 (Print)

ISSN 2684-9305(Online) 


\section{PENDAHULUAN}

Pertumbuhan penduduk akan mempengaruhi berbagai aspek kehidupan baik ekonomi, maupun sosial, terutama peningkatan mutu kehidupan atau kualitas penduduk dalam sumber daya manusia yang dibarengi besarnya jumlah penduduk yang tidak terkontrol. Semuanya itu selalau terkait pada penyedian anggaran dan fasilitas kesehatan, pendidikan serta ketersediaan pangan (Larasati, Muda, Batubara \& Suharyanto, 2018). Dilihat dari segi pembangunan, maka jumlah penduduk sangat berpengaruh dengan masalah pembangunan suatu wilayah. Dalam perencanaan pembangunan, data kependudukan memegang peran yang penting. Semakin lengkap data kependudukan yang tersedia maka semakin mudah rencana pembangunan di susun.

Menurut Undang-Undang Nomor 52 Tahun 2009 tentang perkembangan kependudukan dan pembangunan keluarga, kependudukan adalah hal ihwal yang berkaitan dengan jumlah, struktur, pertumbuhan, persebaran, mobilitas, penyebaran, kualitas, dan kondisi kesejahteraan yang menyangkut politik, ekonomi, sosial budaya, agama serta lingkungan penduduk setempat. Di samping itu di sebutkan pula perkembangan kependudukan dan pembangunan keluarga adalah upaya terencana untuk mewujudkan penduduk tumbuh seimbang dan mengembangkan kualitas penduduk pada seluruh dimensi penduduk. Dari definisi tersebut diharapkan adanya keseimbangan dalam pertumbuhan penduduk sehingga kehidupan masyarakat dapat terkendali dan seimbang. (Fahmi \& Pinem, 2018) (Sinurat, Mbina, 2017)

Menurut Karmoto (2004) dalam dasar-dasar demografi, kebijakan kependudukan utama di Indonesia saat ini adalah kebijakan Keluarga Berencana. Kebijakan ini sudah luas diketahui oleh masyarakat, kebijakan Keluarga Berencana ini telah berhasil mengubah pandangan masyarakat yang pro natalis menjadi anti natalis (Chair \& Kariono, 2011),

Peningkatan jumlah penduduk usia produktif secara signifikan, terjadi karena keberhasilan program Keluarga Berencana (KB). Melalui keberhasilan program KB merubah struktur umur penduduk yang ditandai dengan menurunnya rasio ketergantungan penduduk non-usia kerja (0-14 tahun dan diatas 65 tahun) terhadap penduduk usia kerja (15-64 tahun).

KB sendiri memiliki arti yaitu gerakan untuk membentuk keluarga yang sehat dan sejahtera dengan membatasi kelahiran. Hal tersebut bermakna bahwa perencanaan jumlah keluarga dengan pembatasan yang bisa dilakukan dengan penggunaan alat-alat kotrasepsi atau penanggulangan kelahiran seperti kondom, spiral, IUD (Intrauterine Device), dan sebagainya.

Upaya program baru yang dilakukan untuk mempersiapkan Indonesia dalam kedatangan bonus demografi, yaitu dengan pembentukan program kampung KB. Program kampung KB merupakan satuan wilayah setingkat Desa dengan kriteria tertentu dimana terdapat keterpaduan program dan pembangunan sektor terkait dalam upaya meningkatkan kualitas hidup keluarga dan masyarakat.

Yunas (2018) menerangkan bahwa "Pembentukan Kampung KB merupakan salah satu dari realisasi Pemerintah untuk meningkatkan kualitas hidup masyarakat". Hal tersebut sejalan dengan penjelasan Nathalia (2017) yaitu: "Program Kampung KB mendukung salah satu poin Nawacita Presiden Jokowi yaitu dapat membangun masyarakat pinggiran".

Program Kampung KB di Kabupaten Sumedang sudah berlangsung sejak tahun 2016 dengan membentuk satu Kampung KB yang berlokasi di Desa Naluk Kecamatan Cimalaka. Hingga saat ini pembentukan Kampung KB terus berlanjut dengan membentuk satu Kampung KB disetiap Kecamatan, sehingga total 
Kampung KB di Kabupaten Sumedang sebanyak 27 Kampung KB.

Peran yang dilakukan oleh Dinas Pengendalian Penduduk dan Keluarga Berencana (DPPKB) Kabupaten Sumedang pada program Kampung KB yaitu sebagai penggerak, monitoring dan memberi fasilitas untuk menunjang keberhasilan program Kampung KB. DPPKB Kabupaten Sumedang sebagai fasilitator dan penggerak menjalankan delapan fungsi keluarga untuk peningkatan ketahanan dan kesejahteraan keluarga.

Kegiatan pelayanan lain yang ada di Kampung KB yaitu Integrasi lintas sektor berupa pelayanan terpadu antar sektor yang menjadi kebutuhan masyarakat seperti pelayanan KB berupa pemasangan IUD, pemasangan implan, alat kontrasepsi serta kegiatan kesehatan lainnya, pembuatan akta, pembangunan jalan dan pembangunan, penyediaan buku-buku bacaan, dan Pendidikan Anak Usia Dini (PAUD). Sehingga dibutuhkan efektivitas pelayanan yang baik.

Efektivitas pelayanan merupakan kegiatan pengukuran pelayanan yang menyatakan seberapa jauh target kualitas, kuantitas dan waktu dalam pencapaian sasaran dan tujuan yang ditetapkan. Tujuan efektivitas pelayanan sendiri yaitu untuk mendahulukan kepentingan masyarakat dengan waktu yang singkat. Efektivitas pelayanan sangat bergantung pada orang-orang yang bekerja didalamnya. Efektivitas pelayanan akan mempengaruhi hasil yang diinginkan sesuai organisasi. Harapan masyarakat dengan adanya Program Kampung KB yaitu mendapatkan kesejateraan keluarga lewat pelayanan yang dilakukan dan DPPKB Kabupaten Sumedang dapat tanggap dan bertanggung jawab dengan tugasnya sebagai pemberi pelayanan.

Pelaksanaan pelayanan program kampung KB belum optimal terdapat beberapa indikasi yang menunjukan efektivitas pelayanan program Kampung di DPPKB Kabupaten Sumedang belum baik, dengan indikasi-indikasi antara lain: 1) Jumlah personil yang kurang dalam menggerkan program kampung $\mathrm{KB}$ mengakibatkan terjadinya kesalahan dalam penyampaian informasi; 2) Kurangnya tanggung jawab pegawai dalam bekerja. Hal ini terlihat dari tidak semua anggota tim penggerak menghadiri rapat koordinasi kegiatan kampung KB; dan 3) Belum baiknya kerjasama yang dilakukan antar bidang kerja. Seperti adanya pegawai yang bekerja sesuai instruksi sehingga terkadang data dan informasi terkait program kampung KB kurang akurat.

Belum baiknya efektivitas pelayanan Program Kampung KB, diduga disebabkan oleh koordinasi pegawai di DPPKB Kabupaten Sumedang. Pada hakekatnya koordinasi merupakan kegiatan yang dikerjakan oleh banyak pihak dari satu organisasi yang sederajat dan untuk mencapai suatu tujuan bersama dengan kesepakatan masing-masing pihak agar tidak terjadi kesalahan dalam bekerja baik mengganggu pihak yang satu dengan pihak yang lainnya. Dalam melaksanakan koordiasi yang baik agar program kampung KB berjalan efektif maka harus memperhatikan jumlah personil atau tim yang melakukan pelayanan langsung untuk menangani masalah-masalah yang timbul pada program kampung KB. Selain itu tanggung jawab tiap personil harus diperhatikan agar program kampung KB berjalan dengan baik.

Adapun tujuan dari penelitian ini adalah untuk mengetahui seberapa besar pengaruh koordinasi terhadap efektivitas pelayanan kampung KB di Kabupaten Sumedang.

\section{METODE PENELITIAN}

Metode penelitian yang digunakan adalah metode kuantitatif yang memilki tujuan untuk mendeskripsikan dan menjelaskan keberadaan variabel-variabel secara faktual dan hubungan antara variabel yang satu dengan variabel yang lainnya. Sehingga dengan menggunakan 
metode kuantitatif diharapkan dapat menggambarkan objek penelitian serta mengungkapkan fenomena yang dikaji secara sistematis.

Populasi penelitian ini berjumlah 25 orang yang terdiri dari Kepala DPPKB Kabupaten Sumedang, Sekretaris, bidang Advokasi Informasi Penggerakan, bidang Keluarga Berencana, dan bidang Keluarga Sejahtera. Teknik penarikan sampel menggunakan teknik sampling jenuh, dimana semua populasi dijadikan sampel penelitian.

Adapun variabel yang diuji adalah variabel koordinasi dan variabel efektivitas pelayanan. Untuk dimensi koordinasi menggunakan teori dari Manullang (2001) yang terdiri dari: 1) Rantai Perintah; 2) Informasi; 3) Wewenang; 4) Tanggung jawab; dan 5) Tujuan. Dimensi efektivitas pelayanan menggunakan teori dari Ronald (2003) yang terdiri dari: 1) Rancangan Tugas; 2) Komposisi; 3) Konteks; dan 4) Proses.

Teknik pengumpulan data dilakukan melalui observasi, angket, dan dokumentasi. Sedangkan teknik analisis data menggunakan beberapa rumus statistik seperti Perhitungan Porsentase, Uji Spearman Rank, Uji Signifikansi, dan Uji Koefisien Determinasi (Sugiyono, 2006).

\section{HASIL DAN PEMBAHASAN Koordinasi}

Didalam sebuah organisasi terdiri dari berbagai macam sumber daya manusia yang saling bekerjasama untuk mencapai suatu tujuan. Agar tujuan-tujuan tersebut dapat terpenuhi atau tecapai, maka diperlukan koordinasi diantara individu maupun bidang kerja tersebut.

Brench dalam Hasibuan (2007) mendefinisikan bahwa "Koordinasi adalah mengimbangi dan menggerakan tim dengan memberikan lokasi kegiatan pekerjaan yang cocok dengan masingmasing dan menjaga agar kegiatan itu dilaksanakan dengan keselarasan yang semestinya diantara para anggota itu sendiri".

Selain itu, menurut Hasibuan (2007) dalam melakukan koordinasi perlu memperhatikan empat syarat koordinasi yang terdiri dari: 1) Sense of corporation (perasaan untuk bekerjasama), ini harus dilihat dari sudut bagian perbagian bukan orang perorang; 2) Rifalry, dalam perusahaan-perusahaan besar sering diadakan persaingan antara bagian-bagian ini, agar bagian-bagian ini berlomba-lomba untuk mencapai kemajuan; 3)Team spirit, artinya satu sama lain pada setiap bagian harus saling menghargai; dan 4) Espirit the corps, artinya bagian-bagian yang diikutsertakan atau dihargai, umumnya akan menambah kegiatan yang bersemangat.

Berdasarkan hasil penelitian menunjukkan bahwa hasil perhitungan variabel koordinasi sebesar 56,12\% dengan kriteria cukup baik. Hasil perhitungan tersebut dapat dilihat pada tabel berikut ini:

\begin{tabular}{llll}
\hline \multicolumn{5}{c}{ Hasil Perhitungan Porsentase Variabel Koordinasi Per Dimensi } \\
\hline No & Dimesi & $\begin{array}{l}\text { Rata-rata } \\
\text { Per Dimensi (\%) }\end{array}$ & Porsentase \\
& & 53,22 & Kriteria \\
\hline 1 & Rantai Perintah & 60,07 & Cukup Baik \\
\hline 2 & Informasi & 58,57 & Cukup Baik \\
\hline 3 & Wewenang & 53,42 & Cukup Baik \\
\hline 4 & Tanggung jawab & 55,33 & Cukup Baik \\
\hline 5 & Tujuan & $\mathbf{5 6 , 1 2}$ & Cukup Baik \\
\hline & Rata-Rata Keseluruhan & & Cukup Baik \\
\hline
\end{tabular}

Sumber: Hasil Penelitian 2019 
Rentang nilai porsentase untuk kriteria Cukup Baik berada di nilai 52$67,99 \%$, dari tabel hasil perhitungan di atas dapat diketahui bahwa dimensi yang memiliki nilai terendah dan cenderung mendekati ke kriteria kurang baik yaitu dimensi rantai perintah dan tanggung jawab.

Hasil perhitungan tersebut sesuai dengan hasil observasi dan dokumentasi yang dilakukan. Hasil observasi dan dokumentasi menunjukkan bahwa rantai perintah yang terjadi di DPPKB Kabupaten Sumedang belum berjalan dengan baik. Hal tersebut terlihat dari beberapa hal, yaitu: 1) pegawai belum memahami tupoksi dengan baik sehingga belum mampu menginterprestasikan tugas yang diberikan oleh pimpinan; dan 2) ketaatan pegawai terhadap tugas dan wewenang yang diberikan dalam pelaksanaan program kampung KB belum baik.

Rantai perintah merupakan salah satu faktor penting dalam koordinasi, karena hal yang dikoordinasikan didalam suatu organisasi yaitu tugas atau perintah. Hal tersebut senada dengan pendapat Sedarmayanti (2008) yang menyatakan bahwa terdapat dua tipe koordinasi yaitu: 1) Koordinasi Intern yaitu koordinasi yang dilakukan oleh atasan langsung. Dalam koordinasi ini manajer wajib mengkoordinasikan kegiatan-kegiatan bawahan, apakah bawahannya telah melakukan tugas sesuai dengan kebijaksanaannya atau tugas pokoknya; 2) Koordinasi fungsional yaitu koordinasi yang dilakukan horizontal, hal ini disebabkan karena sebuah unit organisasi tidak mungkin dapat melakukan sendiri tanpa bantuan unit organisasi lain, dengan perkataan lain bahwa koordinasi fungsional wajib dilakukan karena unitunit atau organisasi lainnya mempunyai hubungan secara fungsional yang bersifat Intern dan Ekstern.

\section{Efektivitas Pelayanan Kampung KB}

Istilah pelayanan publik menurut Mansyur (2013) disebut juga dengan istilah "Pelayanan kepada orang banyak (masyarakat), pelayanan sosial, pelayanan umum dan pelayanan prima".

Adapun Pelayanan publik menurut Moenir (2006), yaitu "Kegiatan yang dilakukan oleh seseorang atau kelompok orang dengan landasan faktor material, melalui sistem, prosedur, dan metode tertentu dalam rangka usaha memenuhi kepentingan orang lain sesuai dengan haknya".

Azas-azas pelayana publik menurut Keputusan MENPAN Nomor 63 Tahun 2004 yaitu: 1) Transparansi. Bersifat terbuka, mudah dan dapat diakses oleh semua pihak yang membutuhkan dan disediakan secara memadai serta mudah dimengerti; 2) Akuntabilitas. Dapat dipertanggungjawabkan sesuai dengan ketentuan peraturan-peraturan perundang-undangan; 3) Kondisional. Sesuai dengan kondisi dan kemampuan pemberi dan penerima pelayanan dengan tetap berpegang pada prinsip efisiensi dan efektivitas; dan 4) Partisipatif. Mendorong peran serta masyarakat dalam peneyelenggaraan pelayanan publik dengan memperhatikan aspirasi, kebbutuhan dan harapan masyarakat.

Berdasarkan penjelasan di atas, maka diperlukan efektivitas pelayanan di dalam pelayanan publik. Efektivitas pelayanan publik menurut Siagian (2009) yaitu "Penyelesaian pekerjaan tepat pada waktu yang telah ditentukan, artinya pelaksanaan sesuatu tugas dinilai baik atau tidak sangat tergantung pada penyelesaian tugas tersebut dengan waktu yang telah ditetapkan".

Hasil penelitian terhadap variabel efektivitas pelayanan kampung KB Kabupaten Sumedang, menunjukkan nilai sebesar 48,87\% dengan kriteria kurang baik. Hasil perhitungan efektivitas pelayanan kampung KB dapat diihat pada tabel berikut ini: 
Tabel 2

Hasil Perhitungan Porsentase Variabel Efektivitas Pelayanan Kampung KB Per Dimensi

\begin{tabular}{llll} 
No & Dimensi & $\begin{array}{l}\text { Rata-rata Porsentase } \\
\text { Per Dimensi }(\%)\end{array}$ & Kriteria \\
\hline 1 & Rancangan Tugas & 49,78 & Kurang Baik \\
\hline 2 & Komposisi & 46,13 & Kurang Baik \\
\hline 3 & Konteks & 48,02 & Kurang Baik \\
\hline 4 & Proses & 51,55 & Kurang Baik \\
\hline & Rata-Rata Keseluruhan & $\mathbf{4 8 , 8 7}$ & Kurang Baik \\
\hline
\end{tabular}

Sumber: Hasil Penelitian 2019

Rentang nilai porsentase untuk kriteria Kurang Baik berada di nilai 36$51,99 \%$, dari hasil perhitungan di atas di peroleh nilai terendah ada pada dimensi komposisi.

Dimensi komposisi pada variabel efektivitas pelayanan kampung KB menurut Ronald (2003) "Meliputi variabelvariabel yang berkaitan dengan bagaimana karakter dan tim kerja. Bagaimana kemampuan dan kepribadian anggota tim kerja, ukuran tim kerja, fleksibilas tim kerja dan preferensi para anggota untuk bekerja secara tim".

Hasil perhitungan sesuai dengan hasil obeservasi dan dokumentasi. Berdasarkan observasi dan dokumentasi diketahui bahwa terdapat beberapa hal yang kurang baik dalam efektivitas pelayanan kampung $\mathrm{KB}$,seperti ukuran tim kerja yang terlalu sedikit hanya terdapat 4 tim yang terdiri dari 4 orang untuk masing-masing tim. Sedangkan jumlah kampung KB yang harus di bina dan diberikan pelayanan sebanyak 27 kampung KB yang tersebar di 27 Kecamatan di Kabupaten Sumedang. Dengan minimnya anggota tim maka mempengaruhi pelayanan yang diberikan sehingga efektivitas pelayanan kurang baik.

Selain itu, teradapat pula permasalahan pada kerjasama tim antara pihak DPPKB Kabupaten Sumedang dengan pelaksanan kampung KB di setiap kecamatan. Sering terjadi kesalah pahaman atau perbedaan persepsi di dalam penyelesaian pekerjaan sehingga terkadang pelayanan tidak dapat dilakukan dengan maksimal. Ketika pelayanan yang diberikan tidak mampu memuaskan kebutuhan pengguna jasa maka pelayanan tersebut dapat dikatakan tidak efektif.

Dalam melakukan pengukuran efektivitas pelayanan terdapat beberapa kesulitan, baik dari segi keluaran (output) maupun hasil (outcome). Yandiana (2010) menjelaskan bahwa "pengukuran efektivitas sering mengalami kesulitan, karena keluaran (output) yang dihasilkan lebih banyak yang bersifat keluaran (output) tidak terwujud yang tidak mudah dikuantifikasi". Sedangkan Dahim (2011) menjelaskan bahwa " kesulitannya karena pencapaian hasil (outcome) seringkali tidak dapat diketahui dalam jangka pendek, akan tetapi dalam jangka panjang setelah program berhasil".

Oleh karena itu, Danim (2004) memberikan ukuran dari efektivitas pelayanan yaitu; 1) Jumlah hasil yang dikeluarkan, artinya hasil tersebut berupa kuantitas atau bentuk fisik dari organisasi, program atau kegiatan. Hasil dimaksud dapat dilihat dari perbandingan (ratio) antara masukan (input) dengan keluaran (output); 2)Tingkat kepuasan yang diperoleh, artinya ukuran dalam efektivitas ini dapat kuantitatif (berdasarkan pada jumalah atau banyakanya) dan dapat kualitatif (berdasarkan pada mutu).; 3)Produk kreatif, artinya penciptaan hubungannya kondisi yang kondutif dengan dunia kerja, yang nantinya dapat menumbuhkan kreativitas dan kemampuan; dan 4)Intensitas yang akan dicapai,artinya memiliki ketaatan yang tinggi dalam suatu 
tingkatan intens sesuatu,dimana adanya rasa saling memiliki dengan kadar yang tinggi.

\section{Pengaruh Koordinasi terhadap Efektivitas Pelayanan Kampung KB Kabupaten Sumedang}

Hasil perhitungan mengenai hubungan koordinasi terhadap efektivitas pelayanan kampung KB Kabupaten Sumedang diperoleh hasil untuk rhitung sebesar 0,93 dan Zhitung 4,65. Hasil Zhitung lebih besar dari $Z_{\text {tabel }}(4,65<0,398)$ maka dapat disimpulkan bahwa terdapat hubungan yang positif dan signifikan antara koordinasi dengan efektivitas pelayanan kampung KB Kabupaten Sumedang.

Dengan nilai rhitung sebesar 0,93 maka dapat diketahui nilai pengaruh koordinasi dengan efektivitas pelayanan kampung KB Kabupaten Sumedang sebesar 86\%, artinya terdapat pengaruh yang positif dan signifikan antara koordinasi dengan efektivitas pelayanan kampung KB Kabupaten Sumedang.

Pengaruh koordinasi terhadap efektiivtas pelayanan pun tertuang dalam beberapa pendapat ahli mengenai koordinasi dan efektivitas pelayanan. Seperti yang di jelaskan oleh Handoko (2003) bahwa "Koordinasi (coordination) dianggap sebagai proses pengintegrasian tujuan-tujuan dan kegiatan-kegiatan pada satuan-satuan yang terpisah (departemen atau bidang-bidang fungsional) suatu organisasi untuk mencapai tujuan organisasi secara efektif dan efesien".

Selain itu, koordinasi pun merupakan bagian dalam pengukuran efektivitas pelayanan. Hal tersebut tertuang dalam pendapat Steers (1997) yang meyebutkan beberapa ukuran dalam efektivitas yaitu: 1) Kualitas artinya kualitas yang dihasilkan oleh organisasi; 2) Produktivitas artinya kuantitas dari jasa yang dihasilkan; 3) Kesiagaan yaitu penilian menyeluruh sehubungan dengan kemungkinan dalam hal penyelesaian suatu tugas khusus dengan baik; 4) Efesiensi merupakan perbandingan beberapa aspek prestasi terhadap biaya untuk menghasilkan perstasi tersebut; 5) Penghasilan yaitu jumalah sumber daya yang masih tersisa setelah semua biaya dan kewajiban dipenuhi; 6) Pertumbuhan adalah suatu perbandingan mengenai eksitensi sekarang dan masa lalunya; 7) Stabilitas yaitu pemelihara struktur, fungsi dan sumber daya sepanjang waktu; 8) Kecelakaan yaitu frekurnsi dalam hal perbaikan yang berakibat pada kerugian waktu; 9) Semangat kerja yaitu adanya persaan terikat dalam hal pencapaian tujuan, yang melibatkan usaha tambahan, kebersamaan tujuan dan perasaan memiliki; 10) Motivasi artinya badanya kekuatan yang muncul dari setiap individu untuk mencapai tujuan; 11) Kepaduaan yaitu fakta bahwa para anggota organisasi saling menyukai satu sama lain, artinya bekerja sama denagan baik, berkomunikasi dan mengkoordinasikan; dan 12) Keluwesan adaptasi artinya adanya satu rangsangann baru untuk mengubah prosedur standar oprasional, yang bertujuan untuk mencegah keterbukuan terhadap rangsangan liugkungan.

Dengan pendapat ahli di atas maka dapat disimpulan bahwa dengan adanya koordinasi yang baik akan berdampak pada keberhasilan kerja pegawai. Dalam koordinasi, kerjasama tim sangat diperlukan hal ini sejalan dengan keberhasilan yang menimbulkan efetivitas pelayanan yang optimal. Sama halnya dengan program Kampung KB di DPPKB Kabupaten sumedang yang harus memperbaiki koordinasi antar timnya untuk memberikan pelayanan yang maksimal pada masyarakat kampung KB. Jadi, koordinasi yang baik akan sangat berpengaruh terhadap efektivitas pelayanan yang diberikan. 


\section{SIMPULAN}

Hubungan koordinasi dan efektivitas pelayanan kampung KB Kabupaten Sumedang diketahui koefisien korelasi antara kedua variabel sebesar 0,93 dengan kategori sangat baik. Hal ini berarti terdapat hubungan yang positif dan signifikan antara koordinasi dan efektivitas pelayanan kampung KB Kabupatenn Sumedang.

Adapun pengaruh koordinasi dengan efektivitas pelayanan kampung KB Kabupaten Sumedang adalah sebesar 86\% ini menunjukan bahwa koordinasi sangat berpengaruh terhadap efektivitas pelayanan dan 14\% dipengaruhi oleh faktor lain yang tidak dibahas dalam penelitian ini.

Pelayanan akan berjalan dengan baik apabila terjalin koordinasi yang baik pula diantara para petugas pelayanan. Dengan terciptanya koordinasi yang baik maka akan menghasilkan kerjasama tim yang solid, tanggungjawab yang baik terhadap pekerjaan, memiliki komitmen dalam melaksanakan pelayanan, serta mampu memberikan pelayanan yang sesuai dengan target dan sasaran dari program tersebut.

\section{DAFTAR PUSTAKA}

Chair, A., \& Kariono, (2011), Profesionalisme Aparatur Birokrasi (Studi pada Dinas Kependudukan, Keluarga Berencana dan Catatan Sipil Kabupaten Labuhan Batu), Jurnal Administrasi Publik (Public Administration Journal), 1 (1): 1-6

Dahim. (2011). Pengaruh Koordinasi Tim Pengelola Kelistrikan terhadap Efektivitas pemasangan Listrik gratis bagi masyarakat kurang mampu di Kabupaten Sumedang. Skripsi. STIA Sebelas April Sumedang.

Danim, S. (2004). Motivasi Kepemimpinan dan Efektivitas Kelompok. Jakarta: Rineka Cipta.

Fahmi, S, \& Pinem. M.(2018). Analisis Nilai Anak dalam Gerakan Keluarga Berencana bagi Keluarga Melayu. JUPIIS: Jurnal Pendidikan Ilmu-Ilmu Sosial, 10 (1): 112-119.

Hasibuan, M.S.P (2007). Manajemen, Dasar, Pengertian dan Masalah (Edisi Revisi). Jakarta: Bumi Aksara.
Larasati, Muda, I. Batubara, B.M. \& Suharyanto, A. (2018). Peranan Dinas Pengendalian Penduduk dan Keluarga Berencana dalam Pengendalian Pertumbuhan Penduduk. PERSPEKTIF, 8 (1): 13-18.

Mansyur, S. (2013). Efektivitas Pelayanan Publik Dalam Perspektif Konsep Administrasi Publik. Diunduh di http://media.neliti.com/media/publications 228505-ID-Efektivitas-Pelavanan-PublikDalam-Perspektif-Konsep-AdministrasiPublik.pdf/tanggal 22 November 2018.

Manullang. (2001). Dasar-Dasar Manajemen, Jakarta: Ghalia Indonesia.

Moenir, H.A.S. (2006). Manajemen Pelayanan Umum di Indonesia. Jakarta: Bumi Aksara.

Nathalia. (2017). Strategi Komunikasi Bidang Advokasi dan KIE Badan Pemberdayaan Perempuan dan Keluarga Berencana Dalam Menyosialisasikan Program Kampung KB di Panggungrejo Kota Pasuruan. Diunduh di http://Publication.Petra.ac.id/index.php/ilm u-komunikasi/article/view/6173. Tanggal 05 November 2018.

Ronald, O. (2003). Manajemen Sumber Daya Manusia. Jakarta: Prestasi Pustaka.

Sedarmayanti. (2001). Sumber Daya Manusia dan Produktivitas Kerja. Jakarta: Gramedia.

Siagian, S.P. (2009). Manajemen Sumber Daya Manusia. Jakarta: Bumi Aksara.

Sinurat, L., dan Mbina P., (2017), Keadaan Gerakan Keluarga Berencana Di Desa Parlondu Kecamatan Pangururan Kabupaten Samosir. JPPUMA: Jurnal Ilmu Pemerintahan dan Sosial Politik UMA (Journal of Governance and Political UMA), 5 (2): 126-138

Steers, R.M (1997). Efektivitas Organisasi. Bandung: Erlangga.

Sugiyono. (2006). Metode Penelitian Administrasi. Bandung: Alfabeta.

Yandiana, B. (2010). Pengaruh Pelaksanaan Fungsi Koordinasi Camat Terhadap Efektivitas Pelayanan Program Kerja UPTD dalam Rangka Peningkatan Partisipasi Lembaga Kemasyarakatan Desa dan Peningkan Partisipasi Politik dalm Pembangunan Desan di Kabupaten Garut. Skripsi. Universitas Garut.

Yunas, N.S. (2018). Analisa Kontribusi Program Kampung KB Dalam Upaya Peningkatan Program KKBPK di Kabupaten Jombang Provinsi Jawa Timur. Diunduh di http://researchgate.net/publication/328/25 25206 Analisa Kontribusi Program Kampu ng KB Dalam Upaya Peningkatan Program KKBPK Di Kabupaten Jombang Provinsi Ja wa Timur/tanggal 15 November 2018 